\title{
La Rusia de Pedro I y la Francia de Luis XIV en el pensamiento político español de mediados del siglo XVIII
}

\author{
Cristina González Caizán \\ Centro de Estudios sobre la Tradición Antigua en Polonia \\ y en Europa Centro-Oriental (OBTA), Universidad de Varsovia (UW)
}

Resumen

La carta XIX del tomo tercero de las Cartas eruditas y curiosas escritas por el padre Feijoo, dedicada a exaltar la figura del zar Pedro I frente al monarca galo Luis XIV, provocó una airada reacción en algunos sectores de la sociedad española de mediados del siglo XVIII. Más allá de la defensa de los valores y virtudes de uno u otro monarca, el benedictino gallego se puso al servicio del ideario propagandístico de los Borbones españoles difundiendo las ideas ilustradas y tomando para ello como modelo a uno de los déspotas absolutistas más carismáticos del siglo XVII. La controversia estaba servida.

Palabras clave

Absolutismo. Ilustración. Feijoo. Fernando Vi. Marqués de la Ensenada.

CES.XVIII, núm. 16 (2006), págs. 113-130. 
Origen de las refutaciones a la carta XIX del tomo tercero de las Cartas eruditas y curiosas del padre Feijoo

Vamos a examinar la conducta de Pedro el Grande. Oh qué grande en todo! Oh qué superior en todo a la del Rey Francés!".

Ya el consejero real Vicente Bacallar y Sanna, marqués de San Felipe y vizconde de Fuente Hermosa, en una de sus célebres obras sobre la educación de los príncipes, exhortaba a Luis I a imitar a dos de los más grandes monarcas del siglo XVII: Luis XIV, rey de Francia, y Pedro I, zar de Rusia². El primero gozaba dentro de nuestras fronteras de un amplio reconocimiento por parte de la inmensa mayoría de los ilustrados españoles. Luis XIV se presentaba como el modelo de monarca ideal que debía seguir su nieto, Felipe V, y los hijos de éste, el mencionado Luis I y su hermano, el futuro Fernando VI. En comparación con otros monarcas europeos, la idea de superioridad del monarca galo y los logros conseguidos durante su reinado parecían estar bien asentados en las principales cabezas pensantes de la España de principios del siglo XVIII. Sin embargo, otro monarca va a irrumpir con gran fuerza haciendo tambalear la figura del francés: el zar Pedro I Alexéievich. Hasta principios del siglo XVIII, la falta de información existente respecto de Rusia convertía a este país en todo un enigma. Pero esa imagen fantástica se concretó a partir del reinado de Pedro I y, paulatinamente, el reformismo tecnócrata del zar fue despertando gran admiración e interés. Pronto comenzaron a proliferar obras dedicadas tanto a su persona como a su mandato. En 1726, tan sólo un año después de su fallecimiento, apareció en Ámsterdam una de las primeras memorias sobre su gobierno³. En 1731, Jacobo Francisco Fitz-James Stuart, II duque de Berwick y de Liria, y embajador de Felipe V en Rusia durante el periodo 1727-1730, escribió en sus memorias un

1 Benito Jerónimo Feıjoo, Cartas eruditas y curiosas (1742-1760), tomo tercero, carta XIX. Nos servimos del texto tomado de la edición de Madrid de 1774 (en la Imprenta Real de la Gazeta, a costa de la Real Compañía de Impresores y Libreros), tomo segundo (nueva impresión), págs. 200-216. La cita corresponde a la página 210.

2 «En orden á sugetos condignos, no debe el Monarca dexar pase día sin hacer merced al digno de ella, imitando en esto al grande clementísimo Emperador Tito, que decia: Totum Diem perdidimus, quia nullas mercedes fecimis. Grande exemplar ofrecen en este asunto Carlos XII. ${ }^{\circ}$, Rey de Suecia, Luis XIV. ${ }^{\circ}$; y Pedro el Zar de Moscovia». Marqués de SAn FeliPe, El arte de reinar. Dirigido al Señor Rey Luis Primero, por el Marqués de San Felipe, Ministro Plenipotenciario que fue en los congresos de Breda y Utrech, y Embaxador extraordinario en la Corte de Viena, y República de Génova, en Semanario Erudito, que comprende varias obras ineditas, criticas, morales, instructivas, politicas, historicas, satiricas, y jocosas, de nuestros mejores autores antiguos, y modernos. Dalas a luz Don Antonio Valladares de Sotomayor, Madrid, 1787, vol. III, pág. 275.

3 Jean Rousset de Missy, Mémoires du règne de Pierre le Grand, Empereur de Russie. Père de la Patrie \&c. \&c. \&c. Par le B. Iwan Nestesuranoi. Nouvelle Edition Augmentée de Plusieurs Pièces Importantes, Ámsterdam, 1726-1730, 4 vols. 
epílogo titulado Relación de Moscovia donde aumentaba la propaganda a favor del zar. Cinco años después, en 1736, Manuel Villegas Pignatelli, secretario de Felipe V, publicaba también un elogio desmesurado a la figura de Pedro $\mathrm{I}^{5}$. Las especulaciones surgidas en torno a cual de los dos monarcas disfrutaba de una mayor magnanimidad, bien pudieron haber influido para que, en 1750, uno de los máximos representantes de la Ilustración española, el fraile benedictino Benito Jerónimo Feijoo y Montenegro, escribiera dentro del tercer tomo de sus Cartas eruditas y curiosas un «Paralelo de Luis XIV, Rey de Francia, y Pedro el Primero, Zar, o Emperador de la Rusia», en donde se proponía aclarar las dudas respecto a cual de estos dos monarcas merecía en mayor medida «el epíteto de Grandes, que les da la Fama ${ }^{6}$. Su decidida y enfática inclinación por el ruso, provocó la inmediata respuesta de algunos sectores de la sociedad comprometidos con el pensamiento político del país vecino. Nos referimos a las refutaciones que de este paralelo hicieron el ilustrado Agustín Pablo de Ordeñana, mano derecha y principal hombre de confianza del ministro de Hacienda, Marina, Guerra e Indias, Zenón de Somodevilla y Bengoechea, marqués de la Ensenada ${ }^{7}$ y una persona anónima de la que tan sólo conocemos sus iniciales: «J. de F.» ${ }^{8}$.

El manuscrito 1.715 de la sección Raros y Manuscritos de la Biblioteca Nacional de Madrid contiene la correspondencia entre Agustín Pablo de Ordeñana y el padre Feijoo'. Ocho son el total de epístolas intercambiadas entre

4 Jacobo Francisco Fitz-James Stuart, Conquista de Nápoles y Sicilia y Relación de Moscovia. Precede una Noticia de la vida y escritos del autor por A. Paz y Mélia, Madrid, 1890, págs. 247-468. Más datos sobre el viaje del duque en «Diario del viaje del duque de Liria y Xérica», en Colección de Documentos Inéditos para la Historia de España, por el marqués de la Fuensanta, D. José Sancho Rayón y D. Francisco Zabálburu (CODOIN), Madrid, t. XCIII, 1889.

5 Manuel Villegas Pignatelli, Historia de Moscovia y vida de sus Czares, con una descripción de todo el Imperio, su Gobierno, Religión, costumbres y genio de sus naturales, s/l., [1736], 2 vols. Un ejemplar existe en: Biblioteca Nacional, Madrid (en adelante BN), ms. 2-49905/6. José María Sánchez Diana afirma que, para la elaboración de este escrito, el secretario Villegas se basó en las Mémoires de Jean Rousset de Missy, en los Comentarios del barón de Heberstein sobre el rey de Polonia Esteban Batory, en tradiciones orales contemporáneas y en varios tomos de ensayos científicos que la Academia de las Ciencias de San Petersburgo regaló a la de la Lengua Española cuando el duque de Liria fue embajador en Rusia. José María Sánchez Diana, España y el norte de Europa durante la Revolución Francesa, Valladolid, Universidad de Valladolid, 1963, pág. 10.

6 Benito Jerónimo Feijoo, Cartas eruditas y curiosas, pág. 200.

7 Sobre el partido montado por el marqués véase Cristina González CaizÁn, La red política del marqués de la Ensenada, Novelda, Fundación Jorge Juan, 2004.

8 En general, el padre Feijoo sufrió a lo largo de su extensa producción bibliográfica frecuentes ataques a sus obras. Así podemos destacar — entre otros — los emprendidos por el padre Francisco de Soto y Marne, cronista general de la orden franciscana, y los del portugués António Isidoro da Nóbrega.

9 Una transcripción íntegra de las cartas en Cristina GonzÁlez CaIZÁn, «Correspondencia erudita entre D. Agustín Pablo de Ordeñana y el padre Feijoo», en Brocar, Logroño, 23 (1999), págs. 59-86. El profesor Luis Sánchez Agesta reprodujo también una de estas cartas, la fechada en Oviedo el 23 de noviembre de 1750 (Luis SÁnchez Agesta, Escritos políticos de fray Benito Jerónimo Feijoo y Montenegro, Madrid, Instituto de Estudios Políticos, 1946, págs. 535-542). Y en 1783 la Real Compañía de Impresores y Libreros del Reino publicó unos 
ambos ilustrados y, salvo la primera, en la que Ordeñana le expuso al benedictino su incomodidad e inconformismo por la promulgación de un Real Decreto prohibiendo la impresión de libros atacando sus escritos ${ }^{10}$, el resto de la correspondencia está centrada íntegramente en la particular defensa establecida por ambos personajes en torno a las figuras de Luis XIV y de Pedro I. La segunda de las refutaciones, la anónima, apareció publicada en el Semanario Erudito de Antonio de Valladares y Sotomayor en $1789^{11}$. El autor del Semanario asegura en la primera línea del texto desconocer al responsable de la carta objeto del presente estudio:

Nota del editor. El mérito de la obra presente, es comparable con el del sabio Autor, contra quien se escribió. Ignoramos el que lo fue de ella; pero esto, ni dudar si en aquel tiempo se imprimiría ó no, nos detiene para publicarla en nuestro Periódico. [...] Si acaso se imprimió en el tiempo en que se presentó al público el Paralelo que se disputa, no hallándose ningún ejemplar, lo contemplamos como inédita ${ }^{12}$.

adjuntos a las obras de Feijoo con tres de estas cartas que el benedictino gallego escribió a Ordeñana (Adiciones a las Obras del muy ilustre, y reverendísimo Padre Maestro D. F. Benito Jerónimo Feijoo y Montenegro, Maestro General del Orden de San Benito, del Consejo de S. M. \&c, Madrid, Real Compañía de Libreros y Impresores del Reino, [1783]). Sin embargo, en estas Adiciones no se menciona el destinatario de las cartas y tampoco aparecen sus respuestas. (Ibidem, Carta primera, págs. 50-61, Oviedo, 28 octubre 1750; Carta segunda, págs. 61-66, Oviedo 23 noviembre 1750, y Carta tercera, págs. 67-70, [Oviedo], 26 enero 1751).

10 Este Real Decreto, fechado el 23 de junio de 1750, demuestra las buenas relaciones del benedictino con el poder: «Quiere su Majestad que tenga presente el Consejo que, cuando el padre Maestro Feijoo ha merecido a su Majestad tan noble declaración de lo que le agradan sus escritos, no debe haber quien se atreva a impugnarlos y, mucho menos que, por su consejo, se permita imprimirlos». Biblioteca Nacional, Madrid (en adelante, BN), ms. 10.579. Maximiliano Fartos vio en esta disposición de Fernando VI una forma sucedánea de favor ilustrado al estilo de las protecciones de filósofos que hizo Federico II de Prusia (Maximiliano FarTos, «La Ilustración francesa y su difusión en España», en Cuadernos de Investigación Histórica, Madrid, (13) 1993, pág. 156). Agustín Pablo de Ordeñana no participa de esa misma opinión, percibiendo en ella un atraso para el desarrollo intelectual del país. Y así señala a Feijoo cómo también es necesario corregir algunos puntos de sus obras: «Usted mismo, en algunos puntos de ellas, habrá hallado con el tiempo y más madura reflexión bastante que enmendar o rectificar y si ha leído las Observaciones de nuestros marinos Don Jorge Juan y Don Antonio de Ulloa, se habrá convencido de que no son subsistentes las razones con que intenta Usted probar que el mundo es de figura ovalada. Por éstas y otras consideraciones que omito para no hacer más prolija esta carta sería yo del dictamen, salvo el mejor de Usted, que agradeciendo Usted al Rey de lo íntimo de su corazón una honra tan distinguida, le pidiese con eficaz ruego que levantase la prohibición cuando no a favor del Padre Soto y Marne al de los demás que no han incurrido en igual culpa, para que así quede libre el campo a los modestos investigadores de la verdad». Ordeñana a Feijoo, Aranjuez, 30 junio 1750. Carta transcrita en Cristina González CaIZÁn, «Correspondencia erudita», págs. 60-62. No hemos encontrado la respuesta de Feijoo, si es que ésta se produjo.

11 Antonio Valladares de Sotomayor, «Carta. Al Reverendísimo Padre Maestro Feyjoó, Religioso Benedictino, refutándole el Paralelo, que hizo de Luis XIV, Rey de Francia, con Pedro I. ${ }^{\circ}$ Czar de Moscobia», en Semanario Erudito que comprehende varias obras ineditas, criticas, morales, instructivas, politicas, historicas, satiricas, y jocosas, de nuestros mejores autores antiguos, y modernos, Madrid, 1789, págs. 72-130.

12 Semanario Erudito, pág. 72. 
El tono de las dos impugnaciones objeto de nuestro análisis es diferente en la forma, pero difiere poco en su contenido. La refutación de Agustín Pablo de Ordeñana entra en el ámbito de lo privado, de lo personal. En él escuchamos la voz del político, del hombre temeroso de que las críticas lanzadas por Feijoo llegasen a Francia y pudiesen influir negativamente en las relaciones hispano-fran$\operatorname{cesas}^{13}$. Hemos señalado cómo las obras de Feijoo gozaban del favor y protección real y eso era algo bien conocido por todos. A Ordeñana le preocupaba que los franceses pudiesen pensar que detrás de las opiniones del erudito estuviesen las del monarca español. Sin embargo, se cuidó mucho de hacer pública su protesta. Agustín Pablo de Ordeñana era en esos momentos la figura de máxima confianza del marqués de la Ensenada, el ministro más poderoso en la corte de Fernando VI. Haberlo hecho hubiera significado una declaración profrancesa de su grupo o facción y eso era algo a evitar. Ordeñana, desde el segundo párrafo de su primera carta, dejó claro a Feijoo su papel como mero transmisor de las opiniones de los franceses por él conocidos. Pero el benedictino gallego no lo entendió así, y Ordeñana se vio obligado a escribir en su defensa:

No tenía seguridad de que por otro conducto se hallase Usted con noticia de la impresión que hizo en los franceses el Paralelo entre Luis XIV, rey de Francia, y Pedro I, zar de Moscovia, de que me pareció informar a Usted sólo para su precaución sin otro objeto. Usted no lo ha entendido así cuando dice que yo hallé en él una piedra de escándalo para la nación de Francia que de resulta venía a serlo para mí. Este es un supuesto ajeno a la letra y espíritu de mi carta en que a poco que reflexione Usted hallará que observo la más absoluta neutralidad, suspendiendo mi juicio sobre el Paralelo y refiriendo sin parcialidad lo que aquí oí a varios fran$\operatorname{ceses}^{14}$.

Por el contrario, la refutación de «J. de F.» es pública, abierta, escrita con la intención de ser publicada pero, quizá, con pocas posibilidades de obtener una respuesta por parte del benedictino, al menos a priori ${ }^{15}$.

13 «He oído discutir a varios franceses quejándose amargamente de Usted en quien no esperaban que hiciese tanta impresión las especies malignas del rey, limerces [en relación al libro de Henri Philippe de Limiers sobre el Rey Sol], y otros calvinistas expulsos de Francia que ensangrentaron sus plumas contra Luis XIV en odio y venganza por la revocación del edicto de Nantes. Veremos cómo prorrumpe el sentimiento de la nación en París adonde me aseguran se ha remitido una traducción del paralelo hecha con todo cuidado». BN., ms. 1.715. Ordeñana a Feijoo, Madrid, 12 septiembre 1750.

14 BN, ms. 1.715. Ordeñana a Feijoo, Madrid, 12 diciembre 1750.

15 «R. P. entre vuestros hijos, se hallan monstruos, que vos mismo confesais: pero yo pongo especialmente en este número el Paralelo de Luis XIV. Rey de Francia con Pedro I. ${ }^{\circ}$ Czar de Moscovia, que se halla en su libro $3 .^{\circ}$ de varias curiosas y eruditas cartas. Contra este monstruo odioso voy á salir á campaña: este monstruo intento destruir sin injurias, que pueden caer sobre mí, y los vituperios con que en la boca de uno 
Agustín Pablo de Ordeñana ha recibido el tercer tomo de las Cartas eruditas como un presente del benedictino ${ }^{16} \mathrm{y}$, después de felicitarle por encontrar todas las cartas «muy dignas de su autor» ${ }^{17}$, pasa a mostrarle su disconformidad con la intitulada «Paralelo de Luis XIV Rey de Francia, y Pedro el Primero, Czar, o Emperador de Rusia». Ordeñana — junto con sus conocidos franceses- asegura al benedictino haber leído el paralelo detenidamente y todos encuentran que no ha tratado a Luis XIV en su justa medida elevando demasiado la figura del $\operatorname{zar}^{18}$. «J. de F.» le expone también los tres motivos por los que se ve obligado a escribir contra el paralelo ${ }^{19}$.

\section{Impugnaciones al Paralelo. Autores y obras de referencia}

Sócrates moderno (...) es demasiadamente ceñido, le hallo algo vicioso, porque no disimula en él el desafecto reinante en su Nación al Monarca Francés ${ }^{20}$.

En primer lugar vamos a analizar los autores en los que Feijoo se basó para escribir este paralelo objeto de la presente controversia. Y éstos fueron, como el benedictino gallego confesó privadamente a Ordeñana ${ }^{21}$ : Bernard le Bovier

de sus hijos, oprime V. P. á aquellos, que se atreven á hallar algo que decir en los mas preciosos escritos. Yo paso por encima de este riesgo, y aun de otros todavía mayores con que amenaza V. P. en otras partes á estos temerarios insectos». Semanario Erudito, págs. 73-74.

16 «Muy señor mío. Gracias a usted, y se las doy de muy corazón, por el tercer tomo de sus Cartas eruditas que de su orden me entregó el librero Atena». BN, ms. 1.715. Ordeñana a Feijoo, Madrid, 12 diciembre 1750 .

17 Pese a este halago inicial, Ordeñana escribió unos años después: «Este escritor [léase Feijoo] no me ha merecido jamás otro concepto que el de un mediano compilador, con solo el mérito de haber excitado la nación a dejar a su desidia y abandono en punto de ciencias naturales». Ordeñana a Gregorio Mayans, 10 marzo 1753, en Gregorio MAYANS y SISCAR, Epistolario XV. Mayans y los altos cuadros de la Magistratura y Administración borbónica, 1751-1781. Estudio preliminar, transcripción y notas por Antonio Mestre y Pablo Pérez García, Valencia, Publicaciones del Ayuntamiento de Oliva, 1997, vol. II, pág. 153.

18 «No comprenden los franceses qué razón le ha movido a declamar contra Luis XIV sino es la de destruir a este príncipe para poder fundar sobre su ruina la del zar Pedro, imitando en ésto a muchos de nuestros predicadores que creen no elogian bastante en su panegírico al santo del día si no bajan el valor de aquellos, o aquel con quien le comparan». BN, ms. 1.715. Ordeñana a Feijoo, Madrid, 12 septiembre 1750.

19 «Tres motivos igualmente eficaces me empeñan á tomar la pluma contra V. P. en este asunto. Amo las buenas letras, y soy amante de la verdad, y como buen Español, amo como debo á mi nación, y como es justo á la Francesa. [...] mi afecto á la nación Francesa, en que tengo la satisfacción de vivir, y el amor á la España mi patria, tampoco me permiten callar». Semanario Erudito, págs. 74-75.

20 Benito Jerónimo Fejoo, Cartas eruditas y curiosas, pág. 201. El autor del Anónimo contra el paralelo conviene con Feijoo en la imparcialidad del autor del «Expectador Ingles [...] que es apasionado en su modo de pensar, enemigo de la nación Francesa, y en particular de Luis el Grande». Semanario Erudito, pág. 76.

${ }_{21}$ En el paralelo Feijoo asegura haberse basado principalmente en la publicación periódica Le Spectateur, ou Le Socrate moderno [...] y en las Memorias del Reinado de Pedro el Grande de «Yyvan Nestesuranoi». Bentio Jerónimo FeIJoo, Cartas eruditas y curiosas, págs. 201 y 204. 
Fontenelle ${ }^{22}$; Louis Morérì ${ }^{23}$; François Gayot de Pitaval ${ }^{24}$; algunos autores moscovitas no especificados entre los que destaca la figura de B. Iyvan Nestesuranoi ${ }^{25}$ y François Marie Arouet, más conocido como Voltaire. El padre Feijoo se apoyó principalmente en este último autor y en su obra Histoire de Charles XII, roi de Suède ${ }^{26}$ para redactar su paralelo. La razón por la cual el benedictino prioriza el escrito de Voltaire sobre los demás autores es reducir bastante la realidad:

Cuando el citado autor [léase Voltaire] llega a referir la famosa batalla de Pultava [Poltava] habla de los dos príncipes en términos que específicamente apoyan la preferencia que yo concedo a Pedro $1^{\circ}$ sobre Luis 14. El día 8 de julio del año 1709 se dio la batalla decisiva de Pultava entre los dos más célebres monarcas que había entonces en el mundo. Vivía entonces en el mundo Luis 14, luego no era tan célebre como aquellos dos monarcas ${ }^{27}$.

Todos los autores señalados por Feijoo, a excepción de Fontenelle, lo cual no implica necesariamente desconocimiento del mismo, cuentan con un espacio en la librería de Agustín Pablo de Ordeñana ${ }^{28}$. Y algo, cuanto menos, chocante: al ilustrado ensenadista todos los escritores mencionados anteriormente le parecen «despreciables», principalmente Voltaire:

No descubro en qué puede fundar usted el concepto tan alto que forma de él. Sus escritos no corren en la república literaria ni con mediana reputación y últi-

22 Bernard Le Bovier Fontelle, Éloge du tzar Pierre I, Ámsterdam, 1757. Tan sólo hemos podido localizar esta edición.

23 Louis Moréri, Supplément au Grand dictionnaire historique ou Le mélange curieux de l'histoire sainte et profane de M. Louis Moreri, pour servir à la dernière édition de l'an 1732, Paris, 1735, 2 vols.

24 François Gayot de Pitaval, Causes célèbres et intéressantes, avec les jugements qui les ont décidées, Paris, 1734-1741, 18 vols.

25 Desconocemos si Feijoo ignoraba que este seudónimo ruso era utilizado por el escritor francés Jean Rousset de Missy. El libro referido es el ya mencionado Memoires du regne de Pierre le Grand.

26 François Marie Arouet, Voltaire, Histoire de Charles XII, roi de Suède, Basle, 1733. El libro va precedido de un anecdotario sobre Pedro el Grande. (Tan sólo hemos encontrado esta edición, aunque parece que la primera data de 1731).

27 BN, ms. 1.715. Feijoo a Ordeñana, Oviedo, 28 octubre 1750 (la cursiva es de Feijoo). Según esta afirmación, la simple exclusión de Luis XIV de esta batalla llevó al benedictino a pensar que el monarca galo era inferior no sólo ante al zar, sino también ante el rey sueco. Y efectivamente Luis XIV no participó en esta campaña. La batalla de Poltava, inscrita dentro de la llamada Segunda Guerra del Norte (1700-1721), y librada entre Suecia y sus países vecinos, no concernía a los franceses. En aquellos momentos el Rey Sol libraba su propia lucha: la guerra de Sucesión española (1702-1714). Un conflicto dinástico e internacional tras el cual quedó asentada la dinastía de Borbón en el trono de España y sus Indias.

28 Agustín Pablo de Ordeñana poseía una de las bibliotecas más impresionantes del siglo XVIII. Con cerca de 2.000 volúmenes y 711 títulos diferentes, estaba al tanto de las corrientes más novedosas del momento. Véase Cristina González Caizán, Agustín Pablo de Ordeñana. La biblioteca del ilustrado ensenadista, Universidad de La Rioja, tesis de licenciatura inédita, julio 1998. 
mamente ha decaído tanto la de este autor en Francia, que ya no se hace caso de él. Motivo sin duda, que le ha precisado a buscar su fortuna fuera de aquel reino habiéndose transferido a Berlín en donde al presente se halla ${ }^{29}$.

«J. de F.» también opinó sobre los escritores, según su punto de vista, con más poderío tanto de este siglo como del pasado para poder establecer el «Retrato de Luis XIV, sacado de los escritores más autorizados en este siglo y en el pasado» ${ }^{30}$ : Andrew Michael Ramsay ${ }^{31}$, Henri Philippe de Limiers ${ }^{32}$ y Charles Sevin de Quincy ${ }^{33}$. «J. de F.» ataca la figura del zar Pedro I en lo que considera «más Panegírico que Paralelo», basándose en el texto del mencionado «historiador Rusiano Nestesuranoy» [léase Jean Rousset de Missy] y La relación de Moscovia del ya mencionado duque de Liria ${ }^{34}$.

\section{Impugnaciones al Paralelo. Vicios y virtudes de Pedro I y Luis XIV}

Demás de estos vicios [la incontinencia], comunes a los dos Monarcas, otros tres se atribuyen al Rusiano [...] El primero, la intemperancia en orden al vino [...] El segundo, dejarse arrebatar de la ira [...] El tercero, la crueldad ${ }^{35}$.

29 BN, ms. 1.715. Ordeñana a Feijoo, Madrid, 12 de diciembre de 1750. Ordeñana demuestra estar muy bien informado de los acontecimientos intelectuales europeos. Efectivamente, Voltaire había aceptado la invitación de Federico II de Prusia para residir de manera permanente en Berlín. Vivió en esta ciudad dos años y en ella escribió una obra sobre el monarca francés intitulada Siècle de Louis XIV. Libro publicado en 1750 en Berlín bajo el seudónimo de M. de Francheville. La omisión de esta obra en la correspondencia de ambos ilustrados nos induce a pensar en su desconocimiento por parte del público hispano porque, de lo contrario, suponemos, la hubieran mencionado. En el inventario de la librería de Ordeñana efectuado cuatro años después, esta obra sobre Luis XIV sí aparece en el listado. Véase Cristina González Caizán, Agustín Pablo de Ordeñana. La biblioteca del ilustrado ensenadista.

30 Semanario Erudito, págs. 96-109.

31 Andrew Michel Ramsay, Les voyages de Cyrus avec un discours sur la mythologie et une lettre de Frère sur la chronologie de cette ouvrage, Paris, 1727.

32 Henri Philippe de Limiers, Histoire du Regne de Louis XIV: Roy de France et de Navarre, Ámsterdam, 1720, 3 vols. La primera edición data de 1717. Del mismo autor destacamos también la Histoire de Suede sous le Regne de Charles XII, Ámsterdam, 1721.

33 Charles SEvin De Quincy, Marquis de, Histoire militaire du règne de Louis-le-Gand, avec les planes necesaires et un traité particulier de pratiques et de maximes de l'art militaire, Paris, 1726, 8 vols. El único ejemplar que nosotros hemos encontrado es de edición parisina con fecha de 1726 en 8 vols. J. de F. se refiere en su texto al editado en Berlín en 1751 por el mismo autor, Semanario Erudito, pág. 97.

34 «Yo añado a el testimonio del historiador Rusiano Nestesuranoy, el que nos dixo en su relación de Moscovia un gran señor Español [léase Liria]; cuyo nombre, el carácter, las luces, y la sabiduría saldrán por fiadoras de la verdad de todos los hechos que refiere, como que ha sido testigo de vista de los mas de ellos: él sabe dar a la gloria del Czar, lo que no se le podría negar sin injusticia; pero no pasa de aquí: sus guías son la razon y la verdad». Semanario Erudito, pág. 114. «J. de F.» conoce también El Espectador Inglés al cual señala como principal responsable de los vicios que el benedictino atribuye a Luis XIV. Semanario Erudito, pág. 93.

35 Benito Jerónimo Feijoo, Cartas eruditas y curiosas, pág. 203. 
En el paralelo que Feijoo establece de los vicios entre ambos monarcas, podemos comprobar la actitud claramente prozarista del benedictino gallego, una defensa -como luego veremos- montada sobre ingenuos argumentos y asentada en una doble moral. Mientras por un lado Feijoo señala como uno de los desenfrenos más significativos del monarca galo la lascivia ${ }^{36}$, por otro se atreve a defender descaradamente la lujuria del zar:

aun se dice, que en los diez años que mediaron desde el repudio de la primera mujer, hasta su casamiento con la segunda, no tuvo comercio con mujer alguna. Pero a toda su vida trascendió la mancha de repudiar, y cerrar en un Monasterio a su mujer la Princesa Eudoxia, y casarse con otra, viviendo ella, sin que precediese de parte de esta otra culpa, que quejarse de las infidelidades del Zar: pues aunque no falta Autor, que le creyó indiciada de adulterio, fue rebatido por otros mejor informados [...], toda la Rusia está persuadida de su inocencia ${ }^{37}$.

Ante tamaña afirmación, «J. de F.» se pregunta si no es más digna de represión la poligamia del zar que el adulterio del monarca galo. Y lanza a las mujeres españolas la siguiente pregunta:

no es así que la decisión del Padre Feyjoó, os entrega á la mayor desgracia de cuantas tenéis que temer, y no da lugar de pensar, que por esta determinación del Rmo., tomen aún por razón de conciencia, vuestros maridos el partido de abandonaros totalmente a el ejemplo del Czar, antes que el de permitir algún eclipse en la fidelidad que os deben, á la imitación de Luis? ${ }^{38}$.

El benedictino afirma en el paralelo que al zar le dominaban el vino, los licores y la ira. Feijoo perdona al ruso su gusto por los alcoholes por haber sufrido una bárbara educación ${ }^{39}$ y el segundo de los vicios, los accesos y ataque de furia,

\footnotetext{
36 Para el benedictino, Luis XIV cometió una «monstruosa torpeza de despojar al Conde de Montespan de su legítima esposa, para que sirviese muchos años a su lascivia». Benito Jerónimo FEijoo, Cartas eruditas y curiosas, pág. 202.

37 Benito Jerónimo FejJoo, Cartas eruditas y curiosas, pág. 202. Sobre la esposa del zar véase Estanislao de Kostka VAYo, Historia imparcial de la emperatriz Eudoxia Foedorowna, esposa del zar Pedro el Grande, Valencia, Orga, 1981.

38 Semanario Erudito, pág. 81. La institución matrimonial había caído bastante en desuso en España, véase como ejemplo Carmen Martín Gaite, Usos amorosos del dieciocho en España, Barcelona, Anagrama, 1987.

39 «La educación del Moscovita, como ya se insinuó, fue perversa; y nadie ignora cuánto la calidad de la educación influye en todo el resto de la vida. Toda Religión llena de errores, cual es la que profesaba el Zar, turba mucho la vista intelectual de orden a la mortalidad. Ni una, ni otra disculpa se puede alegar a favor de Luis XIV». Benito Jerónimo Feijoo, Cartas eruditas y curiosas, pág. 206.
} 
simplemente deben disculpársele porque intentaba no tenerlos. A «J. de F.» estas justificaciones le parece una barbaridad y se pregunta si «¿es más loable un hombre con mil vicios naturales que otro con mil virtudes adquiridas? ${ }^{40}$. El padre Feijoo no cree que al zar se le pueda tachar de cruel y justifica sus acciones:

El capítulo de crueldad es en el que yo no puedo convenir absolutamente. Es verdad, que Pedro ejecutó muchos, y severísimos castigos, pero muy merecidos de repetidas sediciones, cuyo asunto era despojarle, no solo de la corona, mas también de la vida. A que se añadió, que los Rusianos, gente entonces bárbara, feroz, y dura, sólo podían ser contenidos, proporcionando el rigor a su ferocidad ${ }^{41}$.

Si el zar padecía estos vicios, la culpa era necesario buscarla en su educación y en su religión, ambas repletas de múltiples errores ${ }^{42}$. De todos los vicios señalados parece que a Agustín Pablo de Ordeñana le molestó especialmente que se tachara a Luis XIV de incontinente, replicándole:

Dicen [los franceses] que falta Usted a la verdad, no sin cargo de su conciencia, publicándole incontinente de por vida (...). Este vicio que no se le conoció hasta su amistad con La Vallière [Louise de La Vallière] y tuvo fin en su matrimonio con la Maintenon [Françoise d'Aubigné, marquesa de Maintenon ${ }^{43}$.

De esta forma tan brusca Ordeñana daba por cerrado el asunto de la promiscuidad sexual de Luis XIV. En general, la vida amorosa en la Corte de los Luises despertaba bastantes recelos tal y como Emmanuele-Félicité de Durfort, duque de Duras y embajador francés en España, reportó al ministro de Estado conde de Noailles tras su primera estancia en Aranjuez en $1752^{44}$.

$40 \quad$ Semanario Erudito, pág. 87.

41 Benito Jerónimo Feijoo, Cartas eruditas y curiosas, pág. 203.

42 «La educación del Moscovita, como ya se insinuó, fue perversa; y nadie ignora cuánto la calidad de la educación influye en todo el resto de la vida. Toda Religión llena de errores, cual es la que profesaba el Zar, turba mucho la vista intelectual en orden a la mortalidad. Ni una, ni otra disculpa se pueden alegar a favor de Luis XIV. Su educación fue bella (...) Profesó siempre la Religión Católica Romana». Benito Jerónimo FeiJoo, Cartas eruditas y curiosas, pág. 206. Como se puede observar, los ilustrados españoles concedían una gran importancia a la educación y al papel que ésta podía desempeñar en el desarrollo del individuo y por consiguiente de la sociedad.

43 BN. ms. 1.715. Ordeñana a Feijoo, Madrid, 12 septiembre 1750.

44 «Je ne puis vous dissimuler que les affaires du parlement et du clergé font ici un effet terrible et que le roi d'Espagne en gémit tous les jours. Les uns représentent la France comme le séjour de l'athéisme, d'autres disent que l'autorité royale est totalement perdue et que l'anarchie règne dans touts les ordres, on ne sait que respondre». Archivo del Ministerio de Asuntos Exteriores, París, t. 512. Duras a Noailles, Aranjuez, 21 mayo 1753. 
Hizo el Moscovita en un reinado, de no muy extendida duración, cosas tales, que divididas podrían constituir gloriosos muchos Reyes, y muchos reinados ${ }^{45}$.

Las críticas de Ordeñana y «J. de F.» trascienden el ámbito de lo intelectual y de lo íntimo y personal para instalarse en la arena política. Ambos ilustrados son firmes partidarios de la política llevada a cabo por el monarca galo y defienden sus ideas y proyectos con gran empeño. A Agustín Pablo de Ordeñana le molestó enormemente el despojo que el benedictino gallego hizo de la figura de Luis XIV, eliminando todas sus virtudes y todos sus méritos para atribuírselos exclusivamente a sus "géneros y ministros» ${ }^{46}$. Feijoo defendía un tipo de monarca ideal en donde el rey fuese «cabeza y mando» y no dependiese de ministros ni de consejeros; ahí es donde el benedictino gallego encontró otra de las piedras angulares de la superioridad de Pedro I sobre Luis XIV ${ }^{47}$. Ordeñana, firme partidario de la política estatalizadora llevada a cabo en España desde los tiempos de Felipe V, tiene en mente el modelo de administrar el país al estilo de Luis XIV de Francia. Para defender las actividades del monarca galo, el ilustrado ensenadista escribió al benedictino gallego cuáles debían ser las virtudes que distinguían a un verdadero monarca del que no lo era. Y, por supuesto, el brazo derecho del marqués de la Ensenada vio todas ellas reflejadas en la figura del Rey Sol. La virtud primera de un monarca estaba en estrecha relación con la religión ${ }^{48}$. Agustín Pablo de Ordeñana presentó a Luis XIV como un monarca devoto pasando a enumerar los eventos religiosos más trascendentales de su reinado y con los que se identifica plenamente: la revocación del edicto de Nantes (1685) ${ }^{49}$, la promulgación de la bula Unigenitus (1713) y las expediciones de misioneros para predicar y establecer el evangelio en África, Asia y América. El zar, según Ordeñana, en este punto, no puede calificarse más que de un mero deísta ${ }^{50}$.

\footnotetext{
45 Benito Jerónimo Feijoo, Cartas eruditas y curiosas, pág. 210.

46 Según Ordeñana, en los aciertos de los ministros es determinante «la buena dirección del Príncipe, debiéndose alabar que los haya elegido». BN, ms., 1.715. Ordeñana a Feijoo, Madrid, 12 septiembre 1750.

47 «Todo o casi todo [léase Pedro I] lo hizo por sí mismo siendo él solo cabeza y mano, rey y ministro, director y ejecutor, agente e instrumento». BN, ms., 1.715. Feijoo a Ordeñana, Oviedo, 28 octubre 1750.

48 «[la religión] es y debe ser en orden, dignidad y aún atribución la primera de las virtudes que constituyen el verdadero heroísmo». BN, ms., 1.715. Ordeñana a Feijoo, Madrid, 12 diciembre 1750.

49 Feijoo en su Paralelo había manifestado en relación con el edicto: «La herejía estaba enteramente desnuda de fuerzas, cuando fue la revocación del Edicto de Nantes. (...) Lo proprio (sic) digo de todo lo demás que quieran aplaudir en este Príncipe. Cuando entró en el gobierno, estaba la Francia enteramente pacificada, los disturbios de la minoridad extinguidos». Benito Jerónimo Feıjoo, Cartas eruditas y curiosas, pág. 209.

50 «El Zar Pedro que no profesó religión alguna, habiendo sido a lo menos un mero deísta». BN, ms., 1.715. Ordeñana a Feijoo, Madrid, 12 diciembre 1750. Si bien es cierto que en el Paralelo Feijoo se lamenta
} 
La segunda virtud del monarca galo señalada por Ordeñana es su alto significado de la justicia. Máxima que únicamente pudo cumplirse gracias al gran despliegue legislativo y racionalización administrativa dictado durante el gobierno del Rey Sol. El principal objetivo de ese magno proyecto era fortalecer el poder del Estado, modelo que la rama española de los Borbones — principalmente por medio de sus ministros — estaba implantando en España desde la llegada al trono de Felipe V. El volumen de ordenanzas y reglamentos promulgados durante los tiempos de Luis XIV fue verdaderamente espectacular. Agustín Pablo de Ordeñana admiraba esta capacidad legislativa y tanto en su biblioteca como en la de su patrón y ministro, marqués de la Ensenada, afloran gran cantidad de libros referidos al gobierno y la administración de Francia, lo que demuestra el interés de ambos políticos por la forma de gobernar en el país vecino ${ }^{51}$. Siguiendo esta línea, el entorno del ministro Ensenada intentó redactar un Código Fernandino a imitación del de Luis XIV en Francia o de Federico II en Prusia ${ }^{52}$.

La admiración del ilustrado ensenadista hacia el monarca galo sube de tono al señalar los medios por los cuales Luis XIV reconstruyó una poderosa flota y una marina respetable capaz de competir con la inglesa ${ }^{53}$. El rearme naval del francés sirvió de fuente de inspiración para el practicado en España por el ministro de Marina, marqués de la Ensenada. En este punto su política de construir y renovar arsenales y astilleros, formar marina y marineros, becar a estudiantes para que aprendiesen técnicas — no sólo navales — en el extranjero, importar libros y documentos, invertir en operaciones comerciales en secreto o el haber ofrecido atractivas pagas para importar técnicos sobre todo, pero no sólo, de Inglaterra y Francia, son algunos de los ejemplos de política ensenadista que

de que el zar no implantase la «verdadera religión en sus Reinos», también señala: «Era sin duda capaz de hacerlo; y aun me atrevo a decir, que le sobraban fuerzas para ello [...] Mas para ejecutarlo era menester, que primero la Divina Gracia le desterrase del entendimiento su errada creencia [...] había infinito que vencer, porque es grande la resistencia del error envejecido [...] Con todo aun en esta materia hizo algo, y no muy poco Pedro el Grande; porque desterró algunas de aquellas más crasas supersticiones». Benito Jerónimo FEIJoo, Cartas eruditas y curiosas, págs. 216-217.

51 Un estudio de la biblioteca del marqués de la Ensenada en José Luis GómEz URdañEz, El proyecto reformista de Ensenada, Lérida, Milenio, 1996, págs. 271-299, y sobre la de Ordeñana, Cristina GonZÁLEZ CaIzán, Agustín Pablo de Ordeñana. La biblioteca del ilustrado ensenadista.

52 «Dígame V. m. si se siente con bríos para formar un código de leyes como el prusiano que se llama Federico y otros modernos; en tal caso se podrían dar a V. m. ayudantes». Ordeñana a Gregorio Mayans, 29 diciembre 1753. Gregorio MAYANS y Siscar, Epistolario XV, vol. II, pág. 203. Esta labor quedó paralizada tras la caída ministerial de Ensenada y sus hombres en julio de 1754. Después, en tiempos de Carlos III, también se intentó copiar este código infructuosamente.

53 «Hizo construir [léase Luis XIV] navíos, puertos y arsenales, que no habían establecido las Compañías de Guardias Marinas para criar buenos oficiales. Formó las clases y listas de gente de mar útiles para cualquier pronto armamento, ejercitó la marinería para habilitarla y al fin con estos únicos medios, logró poner su marina en estado de poder competir con las de Inglaterra y Holanda unidas [...] La del zar nunca llegó a este grado de elevación y gloria». BN, ms. 1.715. Ordeñana a Feijoo, Madrid, 12 diciembre 1750. 
produjeron unos óptimos resultados ya en $1754^{54}$. El marqués de la Ensenada y su equipo miraban a América como un floreciente e importante mercado de donde importar materias primas, sobre todo el palo de tinta de Campeche, y colocar productos españoles. Pero para proteger una flota comercial era necesario contar con una marina fuerte y temerosa que asegure esos cargamentos. Los ensenadistas no pudieron evitar mirar a Francia y los logros conseguidos por Luis XIV en este punto.

Agustín Pablo de Ordeñana sentía también gran asombro por las ciudades y palacios levantados durante el reinado del monarca galo. Residencias reales y villas expresivas de una magnánima proyección de su poder. Estas construcciones, ampliamente imitadas por el resto de las cortes europeas, gozaron de la complacencia del ilustrado ensenadista ${ }^{55}$. Para Ordeñana el zar pudo albergar deseos de realizar operaciones similares a las puestas en marcha por el monarca galo, pero no contó con medios suficientes para realizarlos ${ }^{56}$. El ilustrado ensenadista desprecia las actividades manuales del zar que, por el contrario, tanta admiración despertaron en el benedictino y que tan enfáticamente son defendidas por él en su paralelo ${ }^{57}$. Para Ordeñana estas actividades son, sencillamente, una pérdida de tiempo ${ }^{58}$. Mucho más duro es en este punto «J. de F.». Para este

54 Sobre estas prácticas de espionaje industrial protagonizadas en tiempos de Ensenada, véase Cezary TARARA, Szpiedzy i dyplomaci. Wywiad hiszpa ski w XVII wieku (Espías y diplomáticos. Servicios Secretos españoles en el siglo XVIII), Lublin, Werset, 2005.

55 Siguiendo esta línea por el gusto versallesco en España se construyeron los palacios de La Granja de San Ildefonso en la provincia de Segovia y el Palacio de Oriente en Madrid. Casualmente, a mediados de junio de 1754, Agustín Pablo de Ordeñana tomó bajo su dirección las obras del Palacio de Oriente comenzada en 1735. Archivo Histórico Nacional, Madrid (en adelante AHN), Estado, leg. 2.604.

56 En el «Paralelo» Feijoo manifestó los logros conseguidos por el zar: «una Marina de cuarenta Bajeles de línea, y de doscientas Galeras: Fortificaciones según el estilo moderno de todas las plazas importantes: una excelente Política en todas las ciudades principales: una Academia de Marina, a donde todas la Familias Nobles son obligadas a enviar a alguno de sus hijos: Colegios en Moscú, en Petersburg [San Petersburgo], y en Kiof [Kiev] para enseñar las Lenguas, las bellas Letras, y las Matemáticas: Escuelas públicas en Moscú de Medicina, Farmacéutica, y Anatomía: un Observatorio para la Astronomía: Imprentas tan buenas, como las de los Reinos que florecen en policía: una Biblioteca copiosísima, compuesta de tres que compró en Inglaterra, y Alemania, \&c». Benito Jerónimo Feijoo, Cartas eruditas y curiosas, pág. 211.

57 «Cómo hizo Soldados, y buenos Soldado a los Rusianos? Sirviendo él como Soldado desde el ínfimo grado, de donde fue subiendo por los pasos regulares hasta el supremo. (...) ¡Cuanta influencia tendría esto en todos los Rusianos! ¡Qué noble Moscovita se desdeharía de servir con el fusil, o con la granada en la mano, viendo a su Príncipe batir el Tambor! (...) El mismo ejemplo que en las Tropas de Tierra dio en las de Mar, subiendo por todos los oficios (...) ese mismo Emperador de la Rusia, para aprehender la construcción de los Navíos, y enseñarla a sus Vasallos, excitándoles juntamente para que se aplicasen a ella con su ejemplo, dos años estuvo ejerciendo el empleo de Oficial en Amsterdam, (...) Esta fue una especia de heroísmo incógnito hasta entonces en el Mundo». Benito Jerónimo Feijoo, Cartas eruditas y curiosas, pág. 212.

58 «No pasarán por heroicas muchas de sus extravagancias en que tuvo más parte el capricho que la discreción; para ser gran constructor, excelente hombre de mar y perfecto general de tierra (partes que jamás se han visto juntas en un hombre) no necesitaba ser carpintero, grumete, y tambor. Hubiera valido más que el tiempo que inútilmente empleó en ésto lo hubiera dedicado a otras preferibles importancias del gobierno. Para instruir en tan 
personaje la única manera de poner punto y final a la polémica es haciendo hablar al propio zar:

La diferencia que hay ente el heroísmo de Luis, y el mío, es que Luis aumentó mucho por medio de sus virtudes consumada, la gloria de su nación, y yo comencé a formar la gloria de la mía, por medio de talentos, todavía algo lejos de perfectos. Preciso era, Padre mío, que no hubierais pasado de aquí, y teníais motivo bastante para un Panegírico. Pero quisisteis seguir un falso resplandor, que os cegó del todo: vuestras maravillas preferidas á una verdad sencilla me deshonran. ¿Qué idea fue la vuestra en querer establecer un heroísmo sobre hechos que no fueron otra cosa de mi parte, que una pura diversión ${ }^{59}$.

Más allá del Paralelo. Continúa la controversia entre Feijoo y Agustín Pablo de Ordeñana

Soy con Usted en que demos punto a nuestras conferencias sobre el Paralelo porque no habiendo servido las razones con que le he impugnado, sino de empeñar más a Usted en su defensa ${ }^{60}$.

El fuego cruzado mantenido por Agustín Pablo de Ordeñana y el padre Feijoo nos permite ahondar un poco más profundamente en los pensamientos políticos y modelos de Estado que ambos ilustrados defendían. Y es aquí precisamente donde el benedictino se nos presenta como propagandista del nuevo régimen instaurado por los Borbones. Según este «ideario» un monarca debía buscar ante todo - y por encima de todo - la paz y la felicidad de sus vasallos. Por eso critica la política de conquistas ejercida por Luis XIV:

Nunca serán objeto de mi elogio los Príncipes apellidados grandes solo por sus conquistas [...] lo que constituye los ilustres reyes y dignos de imitación de la posteridad no es supeditar a sus vecinos, sino hacer felices a sus vasallos. Es mucho más difícil y pide mayor capacidad lo segundo que lo primero. Porque lo primero de parte del conocimiento no pide mas que pericia militar, lo segundo necesita de una extensión de luces dilatadísima [...] Quiero al príncipe pacífico, mas no cobarde,

ínfimos ejercicios a sus vasallos bastábanle los operarios y prácticos que trajo de fuera, si lo hizo por inspirar en ellos la subordinación no era menester tanto en unos hombres casi esclavos que no conocían más principio de obrar que la voluntad absoluta y despótica de su soberano». BN, ms., 1.715. Ordeñana a Feijoo, Madrid, 12 diciembre 1750.

59 Semanario Erudito, págs. 120-121.

${ }^{60}$ BN, ms. 1.715. Ordeñana a Feijoo, Madrid, 28 febrero 1751. 
moderado más no insensible, religioso mas no encogido, y en fin que los confirmantes le vean apacible, pero armado con la espada envainada, pero ceñida ${ }^{61}$.

A Fernando VI, primer monarca Borbón nacido en España — dejando al margen el breve reinado de ocho meses de su hermano Luis I-, se le presentó oficialmente como un dulce padre de sus vasallos, pacífico y por encima de todo español. La imagen de un Fernando VI tranquilo alcanzó niveles de razón de Estado ${ }^{62}$. La necesidad de exaltar los valores patrios hizo que Feijoo se pusiese al servicio de la monarquía como difusor de todo este programa; de ahí su visión paternal, reformista y españolista de Fernando VI. La agresión del benedictino contra Luis XIV y las instituciones francesas se fundamentan principalmente en este último punto, tal y como señaló el profesor Antonio Mestre ${ }^{63}$. Incluso este empeño feijoniano por elevar la figura de Pedro I en detrimento de Luis XIV, le llevó a comparar al zar con Fernando VI, calificando a ambos reyes de «pacíficos»:

¿Qué cuidados vemos en él [Fernando VI] sino los mismos que el monarca rusiano? Conducir artífices, maestros, instrumentos, no sólo para el uso más también para la enseñanza de ciencias y artes útiles, promover el comercio activo, colocar sobre un buen pie la marina, construir arsenales, fortificar puertos, en fin procurar con varias providencias la seguridad y comodidad de sus vasallos sabiendo que ésto es lo que constituye un rey grande, glorioso, excelente. Y no llover fuego sobre sus vecinos, derribar muros, inundar de sangre las campañas ${ }^{64}$.

El paralelo que Feijoo establece entre el monarca español y el ruso hizo estallar al ilustrado ensenadista. Agustín Pablo de Ordeñana apoyaba la política de conquistas del monarca galo porque, aseguraba, en la ampliación de territorios está la base del progreso industrial y del comercio ${ }^{65}$. Ordeñana posee suficientes

61 BN, ms. 1.715. Feijoo a Ordeñana, Oviedo, 23 diciembre 1750.

62 Por ejemplo, el benedictino padre Sarmiento, amigo personal de Feijoo y uno de sus más fieles veladores en la Corte, desarrolló todo un programa iconográfico para la decoración del Palacio Real resaltando las virtudes de Fernando VI y su reinado. Incluso llegó a establecer una diferencia entre Felipe V —comparándolo con el guerrero David — y Fernando VI — como el prudente y pacífico Salomón—. Todo el panegírico en AHN, Estado, leg. 2.604. También existe un proyecto del marqués de la Ensenada para la decoración de este palacio fechado el 20 de mayo de 1754. Archivo General de Palacio (Madrid), Obras de Palacio, leg. 355.

63 «Su actitud [léase Feijoo] encajaba, además, con los intereses políticos de la nueva dinastía que encontró en la actitud de Feijoo un apoyo para sus ideas de nacionalismo español dentro de un reformismo moderado». Antonio Mestre y SAnchís, «Reflexiones sobre el marco político y cultural de la obra de Feijoo», en Apología y crítica de España en el siglo XVIII, Madrid, Marcial Pons, 2003, pág. 179.

64 BN, ms. 1.715. Feijoo a Ordeñana, Oviedo, 23 diciembre 1750.

65 En este sentido, Ordeñana manifestó a José de Carvajal su disconformidad con el reciente acuerdo firmado por Fernando VI prohibiendo el comercio con Dinamarca por las relaciones del gobierno danés con el de Marruecos. El ilustrado ensenadista entendió esta disposición como un atraso para los intereses patrios al 
conocimientos sobre el tema, en su biblioteca posee toda la literatura necesaria. Así cuenta con, por ejemplo, las obras del padre del derecho internacional moderno, Hugo Grotius: Mare liberum y De iure belli ac pacis ${ }^{66}$. En ambos libros existe un intento por parte del holandés de legalizar la guerra y justificarla racionalmente. Ordeñana señaló al benedictino gallego que, si excluía a Luis XIV como monarca ideal por conquistador, también debía hacerlo con el zar, pues en este punto demostró una «ambición desbordada» ${ }^{67}$. No obstante, el ilustrado ensenadista, lo que bajo ningún concepto estaba dispuesto a consentir, era la comparación entre Fernando VI y Pedro I. Su reprimenda al benedictino resultó voraz, firme y contundente:

Nuestro monarca Fernando y su primo dos veces hermano Luis 15, tienen ejemplos ilustres que seguir sin salirse de su familia en las dos líneas de España y Francia. No necesitan buscarle atenta distancia como la Rusia, ni de un Príncipe extraño, cuyo carácter personal no forma modelo digno y cuyo estudio y mérito se redujo a imitar él mismo y practicar en sus dominios lo que vio establecidos en otros $^{68}$.

El análisis de este juego cruzado nos lleva a pensar que el padre Feijoo quizá podría estar trabajando a la sombra del secretario de Estado, José de Carvajal y Lancáster. La propaganda del benedictino gallego se acopla perfectamente a la defendida por Carvajal, «paz con todos y guerra con ninguno», idea que se ocupó de mantener y alentar en la mente del monarca español ${ }^{69}$. Es bien conocido por la historiografía que ambos ministros, Ensenada y Carvajal, mantuvieron durante sus años en el Gobierno un equilibro político aunque defendieron posturas opuestas ${ }^{70}$ : el pacifismo a ultranza de Carvajal contrastaba con el espíritu más belicoso el del marqués. Tanto para el ministro Ensenada como para su

cerrarse un mercado. Archivo General de Simancas, provincia de Valladolid, Estado, leg. 6.729. Ordeñana a José de Carvajal, s/l., 19 septiembre 1752.

66 Hugo de Groot, Grotius o Grocio, Mare liberum, 1. a edición en 1609; De iure belli ac pacis libri tres, in quibus jus nature et gentium, item juris publici praecipua explicantur, Paris, 1625.

67 BN, ms. 1.715. Ordeñana a Feijoo, Madrid, 31 diciembre 1750.

68 BN, ms. 1.715. Ordeñana a Feijoo, Madrid, 31 diciembre 1750.

69 Este ideario funcionó tan bien que incluso Fernando VI creyó ser el árbitro de la paz en Europa. Sobre la política del secretario de Estado, véase José Miguel Delgado BARRAdo, José de Carvajal y Lancáster. Testamento político o idea de un gobierno católico (1745), Córdoba, Servicio de Publicaciones de la Universidad de Córdoba, 1999; idem, El proyecto político de Carvajal. Pensamiento y reforma en tiempos de Fernando VI, Madrid, Consejo Superior de Investigaciones Científicas, 2001; Julián Molina CorTón, José de Carvajal. Un ministro para el reformismo borbónico, Cáceres, Instituto Cultural El Brocense, 1999.

70 José Luis Gómez UrdáñEz, «Carvajal-Ensenada: un binomio político», en Ministros de Fernando VI, Córdoba, Servicio de Publicaciones de la Universidad de Córdoba, 2002, págs. 65-92. 
equipo, estos años eran de una «paz armada», de una «guerra a la espera». La paz de Aquisgrán de 1748 dejó sin resolver muchos aspectos de los conflictos europeos. El desencadenamiento del conflicto era cuestión de tiempo y el objetivo del marqués era llegar a él lo mejor preparado posible. Para ello, el ministro inició una reactivación de la marina española y preparó todos los medios a su alcance para la guerra. Al principio lo hizo en secreto, pero con el tiempo sus éxitos sobrepasaron todos los límites y en 1754 Inglaterra ya temía la flota y la capacidad bélica de los españoles ${ }^{71}$.

Las cartas intercambiadas entre Agustín Pablo de Ordeñana y el benedictino padre Feijoo datan de septiembre de 1750 a febrero de 1751, cuando el marqués y sus hombres apenas llevaban un par de años desarrollando sus planes. Los ensenadistas eran conscientes de que, cuando llegase el momento, sería necesario negociar con Francia, pues ella sería si aliada en los mares. España, probablemente, iba a poder construir una poderosa flota pero tendría problemas a la hora de encontrar marineros, debido, principalmente, a la escasez de población. El ataque de Feijoo contra el monarca galo podía ser mal interpretado por la facción francesa de la Corte española al creer que Fernando VI pudiera estar detrás de los despectivos planteamientos sobre el monarca galo. Pero no sólo Ordeñana defendió la figura del Rey Sol por interés, sino — según parece— por convencimiento político. Los ensenadistas adoptaron muchos de los proyectos del reinado de Luis XIV al de Fernando VI, donde el reforzamiento del poder estatal de claro sentido centralista y la reactivación de la marina española eran los hitos fundamentales de su programa. Ambos se convirtieron en una de las señas de identidad más características de la historia de las doctrinas políticas de los años cincuenta del siglo xviı español.

Agustín Pablo de Ordeñana estaba en la línea del influjo francés característico del siglo, no manifestando, como hemos podido observar, ningún temor en defender su «afrancesamiento», algo que todavía no despertaba animosidad ni en lo político ni en lo moral. Igualmente, Ordeñana demostró con sus aserciones unos amplios conocimientos históricos y políticos tanto nacionales como internacionales, mucho más agudos y acertados que los planteados por el benedictino gallego. Feijoo pudo calificar a Pedro I de Rusia como rey pacífico y como buen padre de sus vasallos porque, una vez más en la historia, las noticias sobre Rusia llegaban muy distorsionadas y difuminadas a España. Feijoo presentó a

71 Una cita bastante clarividente de los que el ministro Ensenada había conseguido en este punto nos la aporta el marqués de Grimaldi: «Las noticias que V. m. me da de navíos y marina me consuelan infinito. Sé lo que significa el decir V m. que está contento, y que se logra el fin confieso, [...] diga el gordo [léase Keene] lo que quiera con todos sus secuaces». AHN, Estado, leg. 2.499. Marqués de Grimaldi al marqués de la Ensenada, Palermo, 30 de junio de 1754. 
los lectores españoles a un Pedro I pacífico y buen padre para con sus vasallos, cuando - realmente- no fue ni lo uno ni lo otro ${ }^{72}$. Posiblemente su política expansionista y la crueldad que manifestó con su pueblo no encontraron el eco y la difusión suficiente entre la élite intelectual española y aun menos lo específico de la realidad rusa de entonces.

En definitiva, los quiméricos argumentos sobre los cuales el padre Feijoo construyó una imagen falsa del monarca ruso — y que le sirvieron para compararlo a Fernando VI-, podían haber servido igualmente para erigir la figura de Luis XIV. Pero el benedictino gallego no podía ensalzar al monarca francés porque desde Madrid se había apostado por la españolidad como ideología; una españolidad que superase la pasada dependencia francesa. Por eso se buscó un monarca en buena medida desconocido entre los lectores españoles. Lo que quizá el padre Feijoo no pensase a la hora de infravalorar la política de Luis XIV es que el monarca galo gozase de tanta simpatía entre los ilustrados españoles.

72 Véanse varios ejemplos en las monografías existentes sobre el zar: John Lothro MonTLey, Pedro el Grande, autócrata de todas las Rusias, Barcelona, Ave, 1940; Raymond CarTiER, Pedro el Grande, Madrid, 1974; Robert K. Massie, Pedro el Grande: su vida y su mundo, Madrid, Alianza Editorial, 1987; Juan Manuel Carretero, Pedro el Grande, Madrid, Información e Historia, 1996, y Dmitry Sergeyevich Merezhrovsky, Pedro el Grande y el príncipe Alexei, Barcelona, RBA Coleccionables, 2001. 